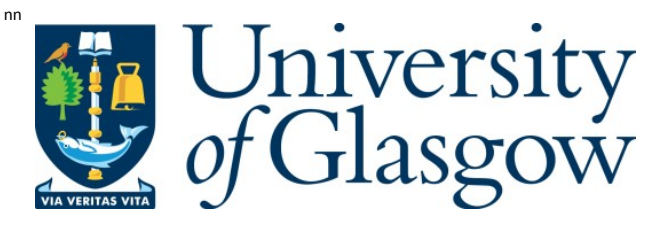

Curzon, P., Cutts, Q. I., and B ell, T. (2009) Enthusing and inspiring with reusable kinaesthetic activities. In: ITiCSE '09 Proceedings of the 14th A nnual ACM SIGCSE Conference on Innovation and Technology in Computer Science E ducation, Paris, France, 3-7 J ul 2009. ISB N 9781605583815. pp. 94-98.

Copyright @ 2009 A ssociation for Computing M achinery

A copy can be downloaded for personal non-commercial research or study, without prior permission or charge

Content must not be changed in any way or reproduced in any format or medium without the formal permission of the copyright holder(s)

http://eprints.gla.ac.uk/45875/

Deposited on: 19 February 2015

Enlighten - Research publications by members of the University of Glasgow http://eprints.gla.ac.uk 


\section{Enthusing \& Inspiring with Reusable Kinaesthetic Activities}

\author{
Paul Curzon \\ Peter W. McOwan \\ Queen Mary University of London \\ Dept of Computer Science \\ London, UK \\ \{pc,pmco\}@dcs.qmul.ac.uk
}

\author{
Quintin I. Cutts \\ University of Glasgow \\ Dept of Computing Science \\ Glasgow \\ Scotland \\ quintin@dcs.gla.ac.uk
}

\author{
Tim Bell \\ University of Canterbury \\ Dept of Computer Science and \\ Software Engineering \\ Christchurch, New Zealand \\ tim.bell@canterbury.ac.nz
}

\begin{abstract}
We describe the experiences of three University projects that use a style of physical, non-computer based activity to enthuse and teach school students computer science concepts. We show that this kind of activity is effective as an outreach and teaching resource even when reused across different age/ability ranges, in lecture and workshop formats and for delivery by different people. We introduce the concept of a Reusable Outreach Object (ROO) that extends Reusable Learning Objects. and argue for a community effort in developing a repository of such objects.
\end{abstract}

\section{Categories and Subject Descriptors}

K.3.2 [Computers and Education]: Computer and Information

Science Education - Computer Science Education.

\section{General Terms}

Human Factors, Design

\section{Keywords}

Reusable Learning Object, Reusable Outreach Object.

\section{INTRODUCTION}

There is widespread concern over the worldwide drop in numbers of students studying Computer Science (CS) subjects. Consequently increasing effort is being placed in outreach programmes. This is proving to be an effective means to reengage school students with the subject. We describe here our experiences from three university projects with schools: the Queen Mary cs $4 f n$ [8] shows, the University of Glasgow CS Inside project [11], and the University of Canterbury Computer Science Unplugged project [3]. Each has developed activities that use low-tech kinaesthetic interaction to explain CS concepts. We recognize that many people have developed and used similar kinds of activities. Our contribution is not the idea of this kind of outreach per se, but in presenting evidence of its wide utility.

We explore here how the same activities, when taking this physical approach to outreach, can be highly successful across a

Permission to make digital or hard copies of all or part of this work for personal or classroom use is granted without fee provided that copies are not made or distributed for profit or commercial advantage and that copies bear this notice and the full citation on the first page. To copy otherwise, or republish, to post on servers or to redistribute to lists, requires prior specific permission and/or a fee.

ITiCSE'09, July 6-9, 2009, Paris, France.

Copyright 2009 ACM 978-1-60558-381-5/09/07...\$5.00. wide range of age and ability groups and in different contexts. They have been used across a wide range of age groups from primary school students to undergraduates and even senior citizens. The same core activities have been used with gifted groups and with general classes, for specialized IT and whole year groups, with small groups and with hundreds, in one-hour class activities and 5-minute lecture demos, for education as part of the school curriculum, as university outreach and for explanations to a lay-jury in court. Feedback has been strongly positive throughout. We also show that activities can be developed such that they can be delivered by different people including teachers and university undergraduates, which is important for scalability.

The low-tech approach works well for these disparate audiences because it is accessible for those with little technical background. For those who do have considerable experience, it is a fresh approach to their area of interest. Being kinaesthetic, it is a contrast to keyboard-mouse-screen interactions normally linked with computing. As no programming is used, there is no barrier (except simple maths skills) to engagement with the material.

We further introduce the idea of a Reusable Outreach Object (ROO) as a variation of Reusable Learning Objects (RLO). Based on our experiences, we argue here that well-designed ROOs are reusable across a wide range of age groups and abilities as well as being reusable by a wide range of presenters. Given the highly reusable nature of this kind of learning object we argue for a community effort in developing new materials. Making more good material available would benefit both universities and schools to deliver better classes and improve uptake of courses.

The paper is structured as follows. In Section 2 and 3 we overview the idea of Learning Objects, introduce Reusable Outreach Objects (ROOs) and overview related work. In Section 4 we discuss the delivery of Artificial Intelligence activities to a range of age and ability groups. In Section 5 we discuss how different core activities have been used from young children to senior citizens in a second project. In Section 6, we show how activities developed for delivery by teachers themselves on a third project have been reused both across different age groups and by a wide range of presenters. In Section 7 we argue for a new push to develop a community-based library of outreach objects.

\section{REUSABLE OUTREACH OBJECTS}

A Reusable Learning Object (RLO) is a learning resource that is made available to others in an easy-to-use way. Different authors use different specific definitions - the following is based on that of Beck [1]. Reusable Learning Objects must be self-contained. A learner or teacher must be able to use them as is, without having to access or create other resources. They must be 
reusable: usable in multiple contexts with multiple overall purposes, by people other than the creator and within different learning contexts (e.g., in different lessons). A less common aspect of reusability is that they be usable across multiple age groups and with groups of different ability: school RLOs are often aimed at specific groups. RLOs must be aggregatable: it must be possible to combine them into larger learning resources such as full learning sessions. RLOs must also include metadata indicating their use (such as potential learning outcomes) so that appropriate RLOs needed for a specific purpose can be easily found. Once found it should also be clear what they are known to be useful for. Many definitions of RLOs require not only that they are available online but that the delivery mechanism is e-learning.

We adapt the idea of Reusable Learning Objects to the context of university outreach. The most important aspect of outreach is that it enthuses the student with interest in the subject. Rather than focusing on learning alone, an outreach object thus has a core aim that it inspires students. It is not sufficient that it just achieves a specific learning objective. To enthuse it should be exciting and enjoyable - it must include a sense of fun. Whilst some RLOs do have this style, and it is arguably good teaching practice, it is not a requirement in the above definition that all RLOs be fun in this way. A Reusable Outreach Object (ROO) is therefore a Reusable Learning Object with a core aim of enthusing about the subject and with the extra requirements of having a fun element. It can be useful if the metadata for a ROO ties it to curricula so that a teacher can justify the use of class time to work on the topic. This also helps presenters choose activities appropriate to specific requests (e.g. a class might have a World War II theme, and the metadata might lead to an activity on cryptographic codes). A ROO can be either a face-to-face or e-learning activity.

Our focus here is on the use of ROOs in live face-to-face settings. We also look at a particular kind of outreach object that is not reliant on computer technology for the activities. Instead we use physical, interactive, kinaesthetic and role-playing methods, making abstract concepts tangible and visible. We do this using the students, the teaching space and everyday objects like cards, rope and tubes to, for example, act out computation scenarios. We argue that this is a good way to provide the fun element of a ROO. It makes the session memorable while making the invisible visible and tangible. This approach is widely used in both school and undergraduate teaching. It is an excellent way to teach that works (as we shall see). A wide range of audiences are able to enjoy it, understand it and appear to remember such activities.

\section{RELATED WORK}

Many Universities engage in CS outreach activities. For example, a range of authors have discussed the use of Lego Mindstorms as an effective form of outreach (e.g. [12]). Environments such as Alice [6] and Greenfoot [15] have also been used successfully in outreach contexts. The cs4fn project (www.cs4fn.org) [8] takes a different approach: a free magazine and webzine taking leading edge research and presenting it in an offbeat way for school students. Outreach shows are linked to cs $4 \mathrm{fn}$, such as the cs $4 \mathrm{fn}$ Magic Show with tricks illustrating CS concepts [9]. Dodds and Karp [13] argue for close liaison over a long period with individual schools. A range of authors have also described the use of kinaesthetic learning techniques, both in teaching and in outreach. For example, Pollard and Forbes [17] argue for the use of hands-on computer-free activities as an effective way to complement university programming labs. Similarly Curzon [10] argued for physical games and puzzles in teaching introductory CS courses. KLA [2] is a wiki-based library for kinaesthetic activities aimed mainly at university teaching contexts.

There are many teaching material repositories. For example CSTA (csta.villanova.edu) and CITADEL (www.citidel.org) have extensive repositories. However, they have aimed for quantity, leaving the user to filter well-developed activities from, for example, Powerpoint slides. They are based on a digital library, and have a generic search system, combined with indexes by category. They are not tied to outreach, although they do include kinaesthetic activities. The UK Higher Education Academy repository of RLOs (www.ics.heacademy.ac.uk/resources/rlos/) is limited to e-learning objects. It is also mainly geared to university rather than school level, though Culwin and Moritario's Cryptography Workbench [7] in the repository has similar outreach aims to the programmes mentioned above.

\section{CS4FN ARTIFICIAL INTELLIGENCE}

We describe first our experiences using a range of ROO activities for schools that were created as part of $\operatorname{cs} 4 \mathrm{fn}$ [8] to enthuse school students about CS. We focus here on activities around the topic of Artificial Intelligence (AI). These same activities have been used as individual elements within a series of larger lectures and workshops. The context has varied from mixed-ability groups including whole class groups and whole year groups, within careers contexts, ICT classes and gifted and talented groups, both at schools and as Saturday school lectures at the University. Ages have ranged from 10 up to 18 . Groups have varied in size from 15 to 200. It provides a good test bed to explore whether this kind of ROO can work across age and ability groups. Three main versions were developed: a Gifted and Talented lecture, a senior school lecture, and a primary school workshop series. Throughout the core goal was to inspire students about CS.

In February 2006 and 2007 we gave a lecture on Artificial Intelligence to a mixed group of 35 and 37 , respectively, mixedage students. It was 2-hour session consisting of students picked by their school as being in the top $5 \%$ of their year. Students from across the UK could attend paying a small fee.

The lecture was structured around our AI ROOs. The overall structure of the talk was to discuss engineering approaches to AI followed by biological approaches. The activities aimed to draw the students into philosophical discussion on what intelligence actually is. For example, one activity involved playing Noughts and Crosses (Tic-Tac-Toe) against a piece of paper with perfect instructions. This led to a discussion on whether blind rule following can be intelligent, given that is what a computer does. A later activity involved building a neural network to play Snap from members of the audience, rope and tubes.

A standard event feedback form was filled in by all participants at the end of the lecture. This was not anonymous and also did not ask for age or sex of the respondent, however the ages ranged from 12-16. Over the two cohorts $90 \%$ agreed that their interest in the subject had grown. $10 \%$ were undecided. $90 \%$ agreed that their understanding had improved, with $1 \%$ disagreeing. Overall $90 \%$ rated the course excellent or very good (Table 1). $94 \%$ said they would recommend the course to others, 1 student would not. 
Table 1. Gifted and talented feedback: Overall rating

\begin{tabular}{|c|c|c|c|c|}
\hline Excellent & V. good & Good & Satisfactory & Poor \\
\hline $46 \%$ & $44 \%$ & $7 \%$ & $3 \%$ & $0 \%$ \\
\hline
\end{tabular}

In 2007/08, a shorter version of this AI talk was given to mixedability classes (11-18 year olds) in schools. This involved dropping some activities and the more philosophical aspects of the talk. The length was tailored for each school ranging from 45 to 90 minutes. The classes varied from whole year groups to small IT classes. Initially only informal feedback was collected from teachers after the event. This was overwhelmingly positive with many schools asking for repeat talks. In the summer of 2008, the talk was given at 12 schools including mixed, all boys and an all girls school. Group sizes ranged from 15 to 200 students. Audiences covered all the age ranges from 11 to 18 . After these the teacher who organized the event was sent a questionnaire which 8 returned. Two others gave informal positive feedback by email. All who returned the questionnaire indicated the talk had met their needs and they would recommend it to other schools/teachers. On 5-point Likert scales all rated the talk positively (see Table 2 ). The activities were repeatedly picked out as the best aspect.

Table 2. Average teacher feedback scores: 1(+ve) to 5(-ve)

\begin{tabular}{|c|c|c|c|c|}
\hline informative & useful & interesting & enjoyable & overall \\
\hline 1.7 & 1.7 & 1.3 & 1.4 & 1.6 \\
\hline
\end{tabular}

The 90-minute lecture was given to a mixed group of over 1009 11 year old students from primary schools in the autumn of 2008 . Post-event informal feedback from the teachers suggested it was well-received and that they would "follow up the topic".

Some of the activities have been used with slightly different learning objectives. For example, the intelligent paper activity has been used with undergraduates to introduce programming, along with other kinaesthetic activities. Feedback was outstanding with the activities frequently named as a reason.

In the summer of 2008, a series of artificial intelligence workshops were held for the whole final year of a primary school to enthuse students about university CS. This was a mixed group of 57 10-11 year olds. The year was split into two classes given the workshops separately as four 2-hour sessions. The above activities were reused and combined with new ones.

The first session's main activity involved students looking for the intelligent behaviour in a series of toys, animals and technology. This led to a discussion of whether intelligence fits on a linear scale (and what it really was). The second week's activity was on the topic of whether computers can learn. It combined the "intelligent piece of paper" activity with the students making their own rules to win the game. This was followed by the creation of a matchbox-learning computer [14]. The third week was on neural networks. This combined making a neural network to play Snap followed by the students, in groups, designing their own neural networks to recognize animals based on features such as "Has stripes". The final session used the kiosk version of Sodarace (www.sodarace.net) [16]. This allows students to experiment with a genetic algorithm that evolves racing creatures for a particular terrain. They also created an emotional "robot" face operated by students following rules (such as "If SUDDEN NOISE then HIGH" for an eyebrow) It was based on a video of a robot that reacts to the tone of someone's voice.

Table 3. Primary school student feedback: Session enjoyable?

\begin{tabular}{|c|c|c|}
\hline Smiling face & Neutral face & Sad face \\
\hline $84 \%$ & $12 \%$ & $4 \%$ \\
\hline
\end{tabular}

The 51 students at the final session filled in an anonymous feedback form. It contained 4 questions. The first consisted of 3 faces: smiling, neutral and sad. It asked students to: "Tick the face that fits how much you enjoyed the sessions". Results were highly positive (see Table 3). Asked about the most enjoyable activity, $11 \%$ indicated the intelligence hunt, $18 \%$ the matchbox computer, $13 \%$ making neural networks, $48 \%$ the on-computer Sodarace activity and $2 \%$ the emotional face. $7 \%$ of responses were that all were the most enjoyable. The remaining $2 \%$ indicated that working with the university team was the most enjoyable thing. Note that there could be a bias towards sodarace as it was in the same session as the feedback was given.

The least enjoyable activity chosen was similarly spread across the different activities. $41 \%$ said "nothing", $14 \%$ suggested the intelligence hunt, $8 \%$ the matchbox learning computer, $20 \%$ neural network, $2 \%$ Sodarace and $2 \%$ the face. $4 \%$ did not enjoy some short robot videos shown and $8 \%$ the parts where the lecturers were "talking". The remaining student wrote that filling in the feedback form was the least favourite activity.

Of the 10 students who least enjoyed the neural network activity. 8 were in one class. Most did not indicate the problem but one explicitly said others in their group "messed about". On this activity, students worked together, especially when constructing their own animal recognition brains. There was a specific problem with one group where some members were disruptive. Of the other 2, one said it was the least enjoyable because they had been away that week (so presumably were disappointed at missing it).

At the start of each session the students were asked questions about the previous session "to remind me what we did". The student's recollection of the main points was good. In the final session, to be one of the students taking part in the face activity, questions based on the content of the previous workshops such as "What is the name of a brain cell?" were asked of the class. Those that knew could put up their hands from which one was chosen and if they got it right they became part of the face. Many students believed they knew answers and generally the person picked did. This suggests that the activities led to learning not just enjoyment. Informal feedback from the teachers was also very positive.

\section{COMPUTER SCIENCE UNPLUGGED}

The second project, we consider here is Computer Science Unplugged (csunplugged.org) [3]. It is probably the earliest and most successful systematic attempt to generate kinaesthetic ROOlike material. It was originally aimed at the 5-12 year-old age group and the activity sheets therefore have a young look and feel. It has since been used across a wider age-range from kindergarten to university, and even senior citizens. This wider use has been expanded recently as part of the CS4HS project [5]. 
Each Unplugged unit covers an entire session (typically around one hour). They provide resources for teachers to help them teach CS principles to their students in a fun and relevant way. They often use multiple activities on one topic (e.g., error correction includes material on parity and the ISBN check digit). Each such activity could be packaged as an individual ROO.

The material has been used in many contexts. For example, although it is packaged as topics that a class can spend an hour on, there is an Unplugged show [4] for 5-12 year olds that uses 5minute presentations of the key ideas of some of the topics, getting the children involved in the kind of thinking required, but not exploring the topic in such depth.

The CS Unplugged material has been used with a large range of students. Many of the activities have been used with primary school classes (age 5 upwards), but also with High School, University, and even adult students. The main difference between how it is used with each group is a slight change of motivation, attitude and language. Because most of the concepts are unfamiliar to all ages, little change in difficulty level is needed.

For example, a magic trick based on parity error correction will generally impress audiences of any age even though parity only requires understanding odd and even numbers. For younger children considerable time can be spent on the concept of odd and even, and the class can count aloud the number of one-bits in each row, whereas for teenagers they will usually recognize the use of even number parity with a little prompting, and won't need any help to count the number of bits! The material has also been used a lot with senior citizens, who again have little trouble working out what is happening, but might need more help explaining the point of error correction in computer storage.

In addition to different age groups, the Unplugged activities have been translated into different languages, including Japanese and Korean, and have been used in a variety of other countries. Occasionally language and cultural differences need to be adjusted for, but to date nearly every activity has been used in multiple countries with little adaptation. In fact, the kinaesthetic nature means that even if a presenter doesn't know the audience's language, much can be achieved by following visual examples.

The Unplugged activities thus further demonstrate the way kinaesthetic activities are reusable across a variety of dimensions.

\section{CS INSIDE}

The final project we consider is the Computer Science Inside project [11]. Its roots are in the Unplugged tradition, with two specific additional aims beyond developing kinaesthetic activities.

The first aim is to use the technology that is already all around young people today as a motivational key to engage them with the science that is inside. For example, cell phone predictive texting is used to introduce machine learning. In any given group, young or old, only around half use the predictive texting facility on their phones. The reasons why form a great discussion starter leading to an activity exploring the underlying mechanisms and science.

The second aim recognises that there will never be sufficient numbers of university and science communication staff to reach all school pupils, and so it is essential that teachers are able to pick up and use the materials themselves.

The initial approach was to visit schools and present activities to computing classes, and thereby make the teachers aware of the resources so that they would adopt them on their own. Resources for all the activities are available on the web. This method was partially successful, with some teachers from the schools visited, and many others from around the world picking up the activities from the web and using them with no further assistance.

Such teachers appear to be the exception however. Many teachers are apprehensive about using teaching methods that involve pupils, for example, working in groups, solving problems or running around the class, with only guidance notes, handouts and presentation slides to help them. Or else, they indicate they don't have enough time to prepare - they may believe that considerable preparation is required if they are to teach a topic on which they are not expert. Because of this, the project has explored how to encourage such teachers to be more willing to adopt this kind of teaching practice. The activities have been presented in the University or in local 'hub' schools all around the country, with the teachers acting in the pupils' role. This is an extremely cheap form of teacher development, and is usually enough to encourage the teachers to try out the activities in their own classes; additionally, enhancements and suggestions from the teachers, with their wealth of experience in front of pupils, support the ongoing improvement of the materials. These developing teacher hubs are excellent for promoting support networks among teachers and for strengthening school-university relations. Similar methods have been used with visiting Korean teachers, and with teacher trainee and science communication classes. Where physical gatherings are not possible, an alternative method for encouraging take-up of the materials, already used by CS Unplugged, is to video the activity in operation.

The CS Inside website (csi.dcs.gla.ac.uk) has around 500 registered users: 300 of these are from Scottish schools; the remainder are teachers and university staff in another 15 countries from Peru to Botswana. Feedback has been received from around 50 teachers on their use of the materials. 43 have used one or more of the CS Inside activities (some have used ten) with their classes and in so doing directly worked with over 2000 pupils. Typical comments are "Comprehensive [activity] packs were more than adequate for preparation", "Inspire you to teach in a very interesting manner which improves classroom atmosphere and relationships", "Pupils gain greater insight into how computer systems work. [Even] if they don't quite understand everything, they certainly enjoy the challenges inherent in learning proactively", "Pupils said if they act out the task, they understand it better", "Pupils raise questions beyond basic topics".

Those who hadn't run workshops mostly cited the time needed to prepare to use them, or a curriculum already too full to contemplate additional material. For this second reason, the CS Inside project has attempted to balance the provision of ROOs, with their inspirational nature and topics generally beyond typical school curricula, with hybrid ROO/RLOs - learning objects that combine both a ROO's fun and kinaesthetic activity with a RLO's need to cover curricular material. Teachers are keen to adopt such materials: "Very useful to have a practical lesson to deliver a 'dry' subject. Pupils engaged throughout lesson."

Indeed, CS Inside has worked directly with teachers to develop new materials. In a weekend event, 18 teachers, 6 academics and 6 postgraduates worked to develop kinaesthetic activities to cover curricular topics with which teachers knew pupils regularly had difficulty. In a second initiative, a university course has final year 
undergraduates working in schools for a number of days, with one objective being the development of new kinaesthetic workshops.

These activities clearly meet the requirements of a ROO. Many teachers have presented them to students, as have 6 university colleagues, 5 postgraduates, over 20 undergraduates and by home education teachers. The recipients' ages range from late primary through secondary school up to first year university level. 1300 person-hours of teacher training have taken place and 5500 pupils are known to have received one or more workshops.

\section{DISCUSSION}

There is a major effort across the CS community to reengage school students in the subject. Educational theory and experience suggest that a fun, kinaesthetic teaching style is highly engaging. As a result many people are creating outreach objects. Indeed, most post-school institutions probably have at least a few engaging outreach objects that are used on open days, school visits, etc. However, as a community we tend not to share and so not to reuse them; additionally, there is little community-wide development of new shared resources. Past efforts such as the KLA repository [2] appear not to have worked as a community initiative. After high initial activity, little has been added since.

There are reasons for the lack of sharing: the individualistic nature of higher education institutions; the often intense battle over student recruitment; and also because (with exceptions) outreach materials are not part of standard academic output. Additionally, and similarly to the open source community, although people are willing to share their material, they need time to write it up more carefully before they are happy to make it available to others. This is a barrier even though the community would appreciate access to the unperfected material.

It would clearly benefit both higher education for recruitment and schools for better classes and better continuation into later classes if more good kinaesthetic materials were available. We have presented specific evidence on how reusable these objects can be, in two dimensions: different audiences (age, ability, culture etc.) and presenters (teachers, lecturers, undergraduates).

To make an initiative work requires not just the existence of a repository but a community and drivers including an active set of people committed to maintaining standards and adding to it over time. On-line communities built around shared resources are successful if they have a strong sense of community with social ties, make it easy to contribute (for example, a wiki-like facility to allow changes to be made as soon as a need is observed), and also make it easy to find relevant material that the users want to access on a regular basis for their work. People must have confidence that they will find something useful and reliable most of the time. In this respect, CS Unplugged with recent resourcing has increasing use and development through its on-line portal; and CS Inside has invested heavily and successfully in the creation of local communities that meet regularly to work with the materials.

We are part of a working group, formed as a result of the recent "Rebooting Computing" summit, to develop a workable community-based repository of good CS kinaesthetic teaching materials in the form of ROOs. We hope this initiative will help build a community that overcomes past problems in this area. The vision is a repository that is the first place to look for material, with an active community and comprehensive set of high quality Reusable Outreach Objects.

\section{ACKNOWLEDGMENTS}

Our thanks go to all who took part in and organised the sessions. The primary school workshops were supported by a Royal Society Partnership grant. cs4fn shows are supported by EPSRC grant EP/F032641/1 and Google. CS Inside is supported by EPSRC grant EP/D507219/1. Margaret Brown and Jon Ritchie are particularly noted. CS Unplugged is supported by Google. The face activity was created with Steve Measure and Steve Brindley.

\section{REFERENCES}

[1] Beck, R.J., (2007) Learning Objects, Center for International Education, UW-Milwaukee, Last accessed 11 Jan 2009. http://www.uwm.edu/Dept/CIE/AOP/learningobjects.html

[2] Begel, A., Garcia, D.A. and Wolfram, S.A. 2004. Kinesthetic learning in the classroom, SIGCSE Bulletin 36(1). 183-184.

[3] Bell, T., Fellows, M. and Witten, I. 1998. Computer Science Unplugged: Off-line Activities and Games for All Ages. Available at: www.lulu.com

[4] Bell, T. 2000. A low-cost high-impact computer science show for family audiences. In Australasian Computer Science Conference (ACSC 2000), pp 10-16.

[5] Blum L., Cortina T.J., Lazowska, E. and Wise, J. 2008. The expansion of CS4HS: an outreach program for high school teachers, ACM SIGCSE Bulletin, 40 (1). 377-378.

[6] Cooper, S., Dann, W. and Pausch, R. 2000. Alice: a 3-D tool for introductory programming concepts, Journal of Computing Sciences in Colleges, 15(5), 107-116

[7] Culwin, F. and Moritario, G. Cryptography Workbench Available at http://www.ics.heacademy.ac.uk/resources/rlos/

[8] Curzon, P. 2007 Serious Fun in Computer Science, ACM SIGCSE Bulletin 39(3) p1. ITiCSE07 Invited Keynote.

[9] Curzon, P. and McOwan P.W. 2008. Engaging with Computer Science through Magic Shows", ACM SIGCSE Bulletin, 40 (3), 179-183.

[10] Curzon, P. 1999. Learning Computer Science through Games and Puzzles. Computers and Fun 2, York, December.

[11] Cutts, Q.I., Brown, M.I., Kemp, L. and Matheson, C. 2007. Enthusing and Informing Potential Computer Science Students and their Teachers, SIGCSE Bulletin, 39(3).

[12] Doerschuk,P., Liu, J and Mann, J. 2007. Pilot summer camps in computing for middle school girls: from organization through assessment, ACM SIGCSE Bulletin 39 (3) 4-8.

[13] Dodds, Z. and Karp, L. 2006. The evolution of a computational outreach program to secondary school students, ACM SIGCSE Bulletin 38(1) 448-452.

[14] Gardner, M. 1969 Further Mathematical Diversions.

[15] Henriksen, P. and Kölling, M. 2004. Greenfoot: combining object visualisation with interaction, Conf. on Object Oriented Prog. Systems Languages and Applications, 73-82

[16] McOwan, P.W. and Burton E.J. 2004. "Sodarace Adventures in Artificial Life" in Artificial Life Models in Software, pp. 97-111. Springer Verlag.

[17] Pollard S and Forbes J. 2003. Hands-on labs without computers, ACM SIGCSE Bulletin 35(1) 296 - 300. 